\title{
ERRATUM
}

\author{
K. Ramesh • H. Huang
}

\section{Use of wheel speed as a parameter to inhibit surface crack generation in the grinding of wear-resistant fillers}

Published online: 16 November 2005

(C) Springer-Verlag London Limited 2005

Int J Adv Manuf Technol (2005)

DOI 10.1007/s00170-004-2209-1

Unfortunately, H. Huang's affiliation was incorrect in the original. The correct version is shown below.

The online version of the original article can be found at http://dx.doi.org/10.1007/s00170-004-2209-1.

K. Ramesh (四)

Faculty of Mechanical Engineering and Manufacturing Engineering,

University of the West Indies,

St Augustine, Trinidad and Tobago

E-mail: ramesh@eng.uwi.tt

Tel.: +1-868-662-2002 ext. 3187

H. Huang

School of Engineering,

The University of Queensland,

QLD 4072, Australia 